\title{
Research on Business Model Innovation based on Shared Economic
}

\section{Concept}

\author{
Jing Ma
}

Xijing University, Xi'an, 710123

\section{Keywords: Shared Economic Concept, Business Model Innovation, Economic Management}

\begin{abstract}
Shared economy is a business model in which individuals, businesses, or organizations share the right to use idle resources through a shared platform and get a return. Cloud computing, large data and other emerging information technology, complex and volatile business competition environment, and light asset model leverage to become a shared economy under the business model innovation driving force. Compared with the traditional business model, the innovation of the business model under the shared economy is characterized by six factors: positioning, business system, key resource capacity, profit model, cash flow structure and enterprise value. Although the development of shared economy is faced with external regulatory environment and other aspects of the resistance, but this business model will eventually bring about the existing business model of subversive innovation.
\end{abstract}

\section{Introduction}

In recent decades, with the rise of large-scale production, large-scale consumption came into being. People in the process of large-scale consumption of a large number of items accumulated, and a large part of which is idle. There is a lot of "consumer surplus" in private hands. In the face of large-scale private consumption surplus, you can reduce the transaction costs through the Internet, improve the allocation of excess resources efficiency, Uber, Airbnb and other shared economic model came into being. The basic characteristics of the shared economy are as follows:

"Consumerism" is a pit that induces consumers to buy too many "useless" items, sharing the economy to provide a new way of trading, to refresh our understanding of "ownership": compared to ownership, more attention to the goods The right to use, by sharing a commodity or service with others, save resources, money, space and time, and even get additional benefits. Pricewater house Coopers' report in 2014 pointed out that $57 \%$ of the new generation of consumers agree with the concept of "sharing that is", that "experience" than "owned" more valuable.

Two observation perspectives. The shared economy can be viewed from both the resource provider and the practitioner. According to a report on the "shared economy" in the EU, there are 1 billion cars in the world, of which 740 million belong to a person alone and dominate, and the use of the day is not more than 2 hours; for the owner There are 3,000 dollars in the house of things that are idle and useless, so there is huge resources to share the economy. "The Queen of the Internet" MaryMeeker released the "Internet Trends Report 2015" (3), the report has a group of very interesting data: the United States freelancer (freelancer) has reached a staggering 53 million, the total $34 \%$ of the labor force, this group is either no stable employer, or spare time to play multiple workers (moonlighter). In other words, from the workers "time sharing" point of view, the shared economy has gradually become the mainstream work. 


\section{Maintaining the Motivation of Business Model Innovation under the Shared Economy}

On the basis of the research results of the innovation of business model innovation, this paper mainly analyzes the three aspects: market power, market environment pressure and market opportunity pulling force.

The marketization of new technologies is one of the driving forces of business model innovation. Business model innovation based on shared economy is realized by the marketization of new technologies. The shared economy is a rapid development in the context of new technologies such as mobile interconnection, large data, and cloud computing. Unlike the e-commerce platform based on the PC (personal computer) -based Internet, the shared economy is a shared platform based on mobile interconnection, Through the supply and demand sides to quickly and accurately match, match the supply and demand sides to achieve the sharing of idle resources. Drop is the business to migrate to Tencent cloud, the use of cloud computing, business stability, security, flexibility, the use of large data algorithms to achieve supply and demand matching and forecasting, accurate marketing, user portrait and automatic billing and other functions.

The new industrial revolution has caused the comprehensive change of the enterprise competition paradigm. The competitive environment of enterprises is faced with strong volatility, uncertainty, complexity and ambiguity. The hyper-competitive environment will become the new normal state of the enterprise. In this case, the enterprise value creation model, the main body, the source and the process will be an important change, only the value of the stakeholders to share the real value of the enterprise to create. From the perspective of business operations, in a highly competitive environment, companies must implement organizational operations of flat, agile and flexible, in order to cope with complex and volatile external environment pressure, which means that the original organization Structure, organizational boundaries are bound to a fundamental change. Shared economy this business model itself has the flexibility, no border is precisely for the enterprise to provide a good opportunity.

Often, companies tend to "have" more resources, through the resources of the "big and complete" to expand their own strength, this heavy asset model is often the result of organizational operations of the rigid, high operating costs and lower profit margins The In fact, the value of resources in essence is its use value, only the use of resources to maximize the value, can fully reflect the value of resources itself. From this perspective, in most cases, the shortage of resources encountered by enterprises is often caused by the use of resources is not enough, not the real lack of resources. Especially for start-ups, entrepreneurs in the resource-poor entrepreneurial situation, through the value of sharing, make full use of existing, scattered and seemingly no value of resources (especially idle resources) to develop new business opportunities, Support the growth of entrepreneurship, in fact, the process of this resource patchwork, just contributed to the formation of shared economy. Airbnb's three entrepreneurs is the original seemingly no value, the idle living room rented to tourists living, and then found that it contains the entrepreneurial opportunities, it does not have a house, the scale of accommodation is more than the world's largest hotel, the final To achieve success.

\section{The Economic Development Bottleneck in China}

Although the shared economy plays an important role in improving the overall efficiency of the society, the new business model can only reflect its value by supporting its regulatory management system. Share the economy in the "growth period" will also meet some of the "growing troubles", the following appeared in our country several phenomena is a shared platform to solve the problem: 
brush single. O2O model of the rise, the use of online payment + physical store line experience has gradually replaced the traditional consumption habits. But the establishment of the early stage of the platform need to continue to "burn", in order to allow more businesses and consumers into the platform, then the subsidy is the fastest means. Uber just entered our country, the subsidy is very high, the reward is not cap, the face of a lot of money income, driver power, by increasing the time to fight for more, and the consumer market is in the process of growing up Over a period of time oversupply. Drivers in order to get more list and higher income and "pervasive", they established the Uber driver micro-credit group, brush each other, brush a single behavior began to spread in the market. Data show that Uber into the initial high subsidies, some drivers a week net income reached 70,000. China's consumer market, the serious follow-up behavior will taste the sweetness of the performance after more vividly. If there is a large number of shared platform on the single-action, which not only can not achieve the maximum utilization of resources, but also cause more serious waste of resources for the sharing platform is also a hazard, so to curb the single action is a shared platform to solve the urgent solution The problem.

User stickiness. "Careful planning" is the obvious characteristics of our consumers. China's car market in the first-tier cities into three pillars: drop, Uber, Divine car. Uber uses a high reward system to attract drivers to join, with electronic coupons and other discounts to encourage passengers to use. Once the intensity of these subsidies fell, it is bound to make users turn to other car platform. Other sharing platform is the case, the price advantage is not to maintain long-term use of the user means to establish a differentiated competitive advantage and strengthen customer relationship management is the key to retain the user. Uber fashion brand, comfortable ride experience and customer relationship maintenance in the passenger side has gradually formed an advantage, but how to improve the driver side of the user sticky, to ensure that their own resources is Uber should focus on the development direction.

\section{Innovative Elements of the Business Model under the Shared Economy}

Business model positioning refers to the way to meet customer needs, which is the central part of the business model. Under the shared economy, enterprises through information technology to establish a shared platform to match the supply and demand sides to complete the sharing of idle resources, which is different from ordinary B2C enterprises, often passive response to customer needs, but also different from the ordinary C2B business, take the initiative to respond to customer needs Is through the establishment of supply and demand between the "connection", through the large data analysis technology automatically match the two sides, with more flexibility, better able to meet the individual needs of customers.

Business system refers to the enterprises choose to cooperate with the stakeholders and their trading methods, mainly by the configuration, role and relationship of three parts. The structure is the stakeholder and its formation of the network topology, the role is the specific strength of the stakeholders, the relationship between the stakeholders is the relationship between governance. From the structure, the shared economy is mainly composed of the supply side, the sharing platform, the demand side of the three stakeholders to form a network structure, sharing platform is a match between supply and demand of the media, the supply side are mostly idle resources, Decentralized, both supply and demand through the shared platform registered as a user, you can share idle resources as needed. From the role of the transaction, the supply chain and the shared platform, which are different from the vertical supply chain relationship of the traditional enterprises, are a more flat horizontal partnership between the partnership, the alliance, the drop and the windmill owner Between the relationship is that the drop itself does not ride demand, the demand comes from 
the passengers, therefore, the owner is not a drop of vertical sense of the supplier. In terms of governance relations, there is often a relationship between traditional firms and stakeholders, such as pure market transactions, ownership transactions, equity participation, holding, and shared economic and stakeholder (especially suppliers) Kind of partnership, affiliate relationship, in addition to the supply and demand sides of the other stakeholders, in order to complement the resources and capabilities, there may be other governance relations.

Key resource capabilities are important resources and capabilities behind the trading structure. Different business models require different key resource capabilities, and key resource capabilities often determine the level of performance of the same business model. The key resources of traditional enterprises are often based on product quality, R \& D capability, price and so on. The sharing economy is developed with the support of emerging information technology. The sharing platform is its only operating environment. Therefore, information technology becomes a shared economic enterprise One of the key resource capabilities, Robinson logistics company will be information technology as its key resource capacity, the annual investment in information systems construction amounted to more than 50 million US dollars. In addition, the traditional enterprises tend to pay attention to the demand side, the customer resources as an important chip to expand the strength of the shared economic enterprises, the supply and demand sides are influential partners, supply and demand sides of the match and the platform of viscosity and loyalty It is necessary to pay attention to the demand side, but also pay attention to the supply side, at the same time to improve the viscosity of the two sides of the platform, both supply and demand as a key resource for the enterprise Part of the ability.

\section{Conclusion}

Shared economy is the result of technological progress, is the cloud computing, large data, Internet of things and mobile Internet products. Although the development of shared economy also encountered some bottlenecks, from the macro point of view, the direct impact of shared economy is to improve the total supply, bring prices downward pressure, in a short period of time may even deflation situation, but even so, its Negative effects are also extremely limited. The "disruptive innovation" of the shared economy is impacting the traditional business model, which reallocates resources to maximize the use of resources and more performance for the benefit of society.

\section{References}

[1] Lu Weilin. Technology, development path and marketing points of micro-O2O research in mobile Internet horizon [J]. Business Age, 2014 (35)

[2] Wei Li. Music as announced by the financial ecology and O2O strategy "919 Music Festival" welfare upgrade [J]. Internet World, 2016 (09)

[3] Lin Feng. Research on Internet Enterprise Development Strategy Based on O2O Model [J]. Enterprise Reform and Management, 2015 (11)

[4] Li Le. Zhou Hang: do smart O2O service [J]. Manager, 2012 (04)

[5] Jin Dan. Tourism O2O field of the four major changes [J]. Internet Weekly, 2014 (16) 